\title{
Clinical features of single and repeated globe rupture after penetrating keratoplasty
}

This article was published in the following Dove Press journal:

Clinical Ophthalmology

4 March 2013

Number of times this article has been viewed

\section{Noriaki Murata \\ Hideaki Yokogawa \\ Akira Kobayashi \\ Natsuko Yamazaki \\ Kazuhisa Sugiyama}

Department of Ophthalmology, Kanazawa University Graduate School of Medical Science, Kanazawa, Japan
Correspondence: Hideaki Yokogawa Department of Ophthalmology, Kanazawa University Graduate School of Medical Science,

I3-I Takara-machi, Kanazawa-shi, Ishikawa-ken 920-864I, Japan

$\mathrm{Tel}+8 \mathrm{I} 762652403$

Fax +8I 762229660

Email hyoko@med.kanazawa-u.ac.jp
Background: In this paper, we report our experience of the clinical features of single and repeated globe rupture after penetrating keratoplasty.

Methods: We undertook a retrospective analysis of single and repeated globe ruptures following keratoplasty in eight eyes from seven consecutive patients referred to Kanazawa University Hospital over a 10-year period from January 2002 to March 2012. We analyzed their ophthalmic and demographic data, including age at time of globe rupture, incidence, time interval between keratoplasty and globe rupture, cause of rupture, complicated ocular damage, and visual outcome after surgical repair.

Results: Five patients (71.4\%) experienced a single globe rupture and two patients $(28.6 \%)$ experienced repeated globe ruptures. Patient age at the time of globe rupture was $75.4 \pm 6.8$ (range 67-83) years. Four of the patients were men and three were women. During the 10 -year study period, the incidence of globe rupture following penetrating keratoplasty was $2.8 \%$. The time interval between penetrating keratoplasty and globe rupture was $101 \pm 92$ months (range 7 months to 23 years). The most common cause of globe rupture in older patients was a fall $(n=5,79.8 \pm 3.7$ years, all older than 67 years $)$. Final best-corrected visual acuity was $>20 / 200$ in three eyes (37.5\%). In all except one eye, globe rupture involved the grafthost junction; in the remaining eye, the rupture occurred after disruption of the extracapsular cataract extraction wound by blunt trauma.

Conclusion: Preventative measures should be taken to avoid single and repeated ocular trauma following penetrating keratoplasty.

Keywords: repeated globe ruptures, penetrating keratoplasty, postoperative complications, ocular trauma

\section{Introduction}

Globe rupture is a significant postoperative complication after penetrating keratoplasty. Many cases of traumatic globe rupture after penetrating keratoplasty have been reported, with a reported incidence of $1.28 \%-5.8 \%{ }^{1-7}$ Because wound healing at the graft-host junction is delayed by avascularity and long-term use of topical corticosteroids, the tensile strength of a corneal wound is never comparable with that of normal corneal tissue. However, using the PubMed search engine, only two case series of globe rupture after penetrating keratoplasty have been reported from Japan. ${ }^{3,5}$ Moreover, repetition of globe rupture after penetrating keratoplasty has not been adequately described in previous reports. ${ }^{1-7}$ Here we report the clinical features of globe rupture following penetrating keratoplasty in patients referred to a regional core hospital in Japan, and detail the clinical course of two patients who experienced repeated globe ruptures. 


\section{Materials and methods}

The present study was approved by the ethical committee of Kanazawa University Graduate School of Medical Science and followed the tenets of the Declaration of Helsinki. We analyzed the records of consecutive patients referred to Kanazawa University Hospital between January 2002 and March 2012 for globe rupture following penetrating keratoplasty, and included seven cases, regardless of involvement of the graft-host junction. Cases with wound dehiscence caused by infection or suture manipulation, such as adjustment or removal of sutures, were excluded. Our hospital performed 246 penetrating keratoplasties during the study period. Ophthalmic and demographic data were collected on the seven patients identified to have globe rupture, including age at the time of rupture, incidence, the time interval between penetrating keratoplasty and rupture, cause of rupture, complicated ocular damage and the visual outcome after surgical repair. We also documented in detail the clinical course of patients who experienced repeated globe ruptures. All data analysis was performed using Microsoft Office Excel 2007 software (Microsoft Corporation, Redmond, WA, USA). $P$ values $<0.05$ were considered to be statistically significant.

\section{Results}

Table 1 shows the demographic data for our seven patients with globe rupture. Five $(71.4 \%$, cases $1,3,4,6$, and 7$)$ experienced a single globe rupture and two $(28.6 \%$, cases 2 and 5) experienced repeated globe rupture. Patient age at the time of rupture was $75.4 \pm 6.8$ (range 67-83) years. Four of the patients were men and three were women. Our hospital performed penetrating keratoplasty in seven eyes, while penetrating keratoplasty in the remaining one eye was performed at another hospital. Our hospital performed 246 penetrating keratoplasties during the 10 -year study period, and seven eyes in this group (2.8\%) presented with globe rupture. The time interval between penetrating keratoplasty and globe rupture was $101 \pm 92$ months (range 7 months to 23 years). In all except one eye, globe rupture involved the graft-host junction; in case 5-R, traumatic globe rupture involved only the post-extracapsular cataract extraction scleral wound. The cause of globe rupture was a fall in five eyes (62.5\%), being struck in two eyes $(25.0 \%)$, and being poked by a finger in one eye $(12.5 \%)$. Of note, five older patients $(79.8 \pm 3.7$ years, all older than 67 years) experienced globe rupture after a fall. Final bestcorrected visual acuity (BCVA) was $>20 / 200$ in three of eight eyes (37.5\%), and final mean BCVA deterioration was +0.72 logarithm of the minimum angle of resolution (logMAR) from BCVA prior to rupture. Posterior segment damage to three eyes, including vitreous hemorrhage, retinal detachment, and choroidal hemorrhage, resulted in a visual loss of $+1.32 \log$ MAR, whereas four eyes without posterior segment damage experienced a visual loss of $+0.28 \log$ MAR; there was no significant difference between the two groups ( $P=0.12$, unpaired $t$-test). Lens damage in four eyes resulted in a visual loss of $+0.69 \log$ MAR, whereas three eyes without lens damage experienced a visual loss of $+0.43 \log$ MAR; there was no significant difference between the two groups $(P=0.63$, unpaired $t$-test $)$.

\section{Case reports}

\section{Case 2-R}

This was an 80-year-old woman who experienced repeated globe rupture in her left eye. In 1995, she was treated with trabeculectomy, phacoemulsification, and intraocular lens implantation in both eyes. In 2006, her right eye was eviscerated because of a severe bleb infection. In 2007, our hospital performed a successful therapeutic penetrating keratoplasty for a corneal ulcer in her left eye. In 2008 (53 months after surgery), her left eye was ruptured because of a fall that occurred when she was not wearing protective eyeglasses. Graft-host junction dehiscence, vitreous loss, and intraocular lens extrusion were noted (Figure 1A), and repaired by corneal resuturing and anterior vitrectomy (Figure 1B). In 2012, her left eye was ruptured again because she fell from her bed when she was not wearing protective eyeglasses. As a result, total retinal detachment occurred (Figure 1C). Her left eye was repaired by corneal suture, pars plana vitrectomy, and silicone oil tamponade. In 2012, endothelial failure was observed, and the final BCVA in her left eye was 20/2000 (Figure 1D).

\section{Case 5-R}

This was a 67-year-old man who experienced repeated globe ruptures; the first rupture occurred in his left eye and the second in his right eye. Between 1987 and 1989, he was treated with bilateral penetrating keratoplasty and extracapsular cataract extraction for bilateral corneal leukoma and cataract. In 2003 (15 years following surgery), his left eye ruptured when he was struck by a window frame while not wearing eyeglasses. Graft-host junction dehiscence, iris extrusion, and vitreous loss were noted (Figure 2A), and repaired by corneal resuturing and anterior vitrectomy (Figure 2B). In 2011 (23 years after penetrating keratoplasty, 21 years postextracapsular cataract extraction), his right eye ruptured after a 


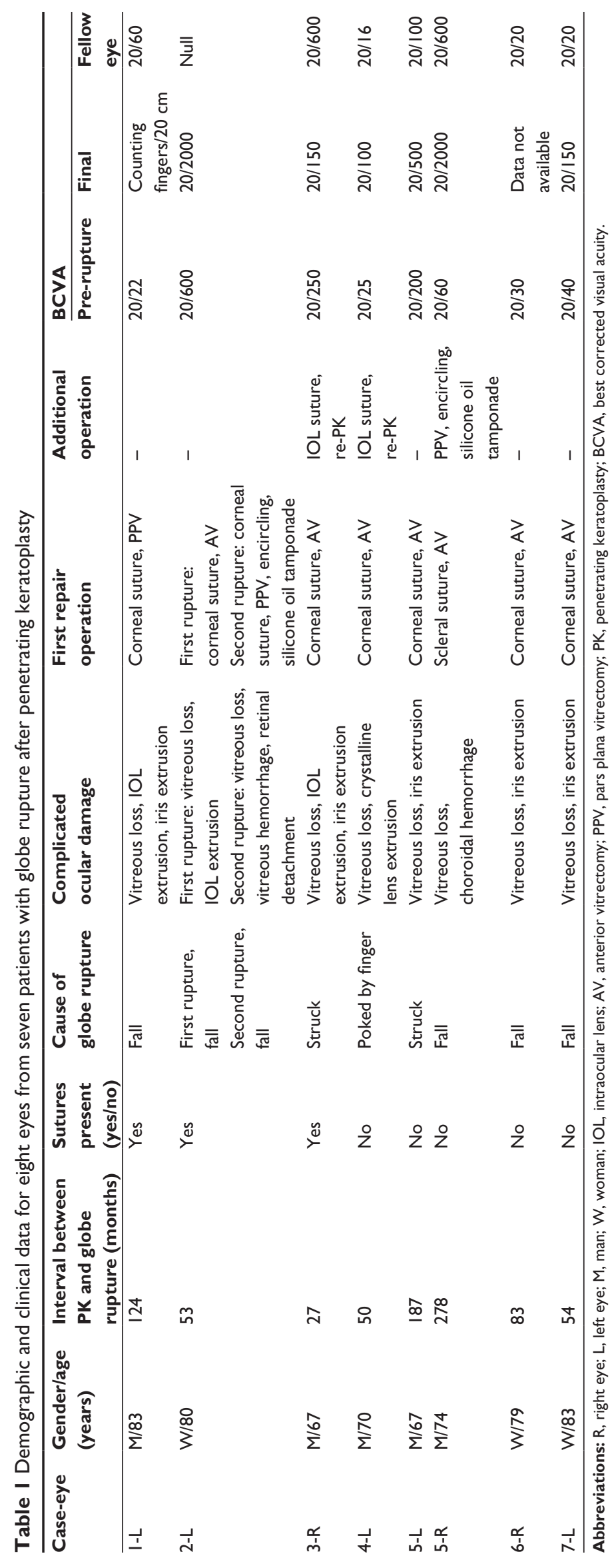



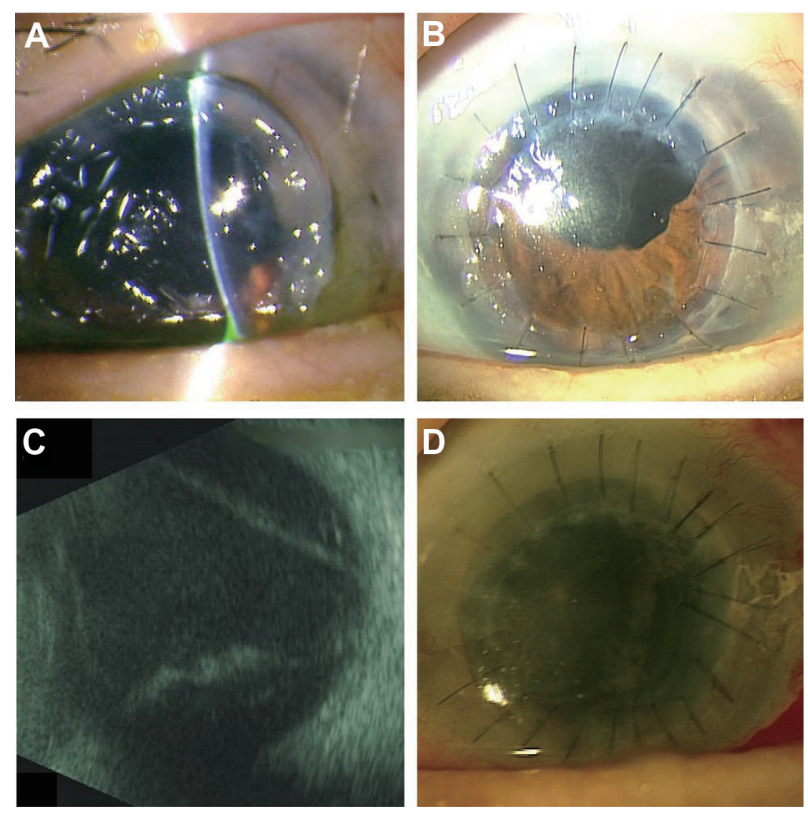

Figure I An 80-year-old woman experienced repeated globe ruptures in her left eye. (A) The first globe rupture was caused by a fall 53 months after PK. Graft-host junction dehiscence, vitreous loss, and IOL extrusion were observed. (B) The first rupture was repaired by corneal suture and anterior vitrectomy. (C) Four years after the first globe rupture, the second globe rupture was caused by a fall from her bed. The ultrasonographic image shows that the retina has totally detached. (D) The second rupture was repaired by corneal suture, pars plana vitrectomy, and silicone oil tamponade.

Abbreviations: PK, penetrating keratoplasty; IOL, intraocular lens.
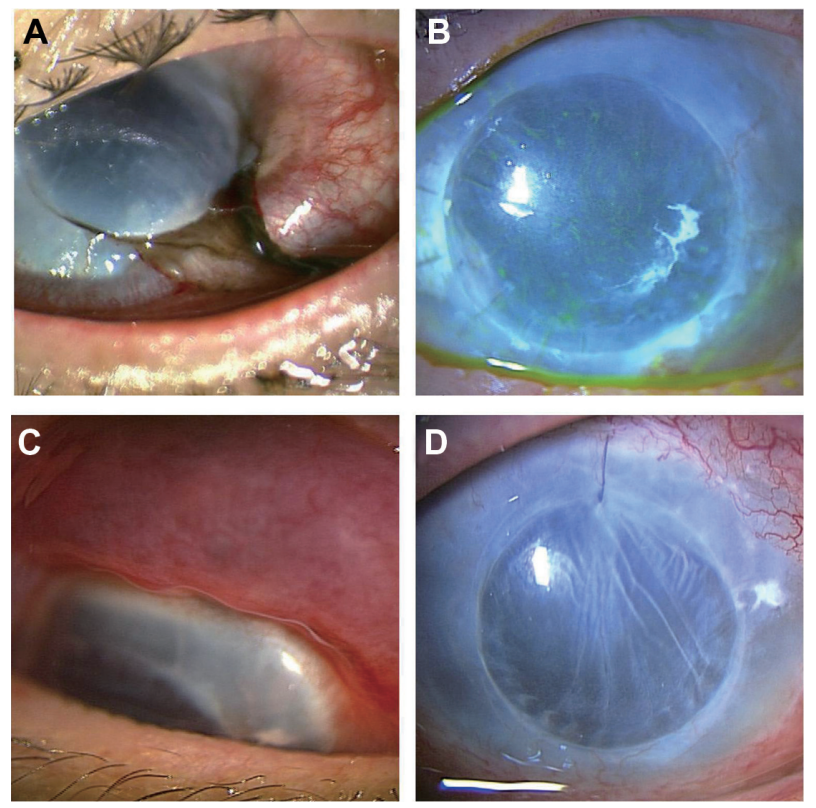

Figure 2 A 67-year-old man experienced repeated globe ruptures; the first rupture occurred in his left eye, and the second was in his right eye. (A) Eleven years postPK, his left eye was ruptured after being struck. Graft-host junction dehiscence, iris extrusion, and vitreous loss were observed. (B) His left eye was repaired by corneal resuture and anterior vitrectomy. (C) His right eye was ruptured by a fall 23 years post-PK. While the graft-host junction was intact, the scleral wound, which had been made at the extracapsular cataract extraction site, was disrupted. (D) His right eye was repaired by multiple operations including scleral suture, pars plana vitrectomy, encircling, and silicone oil tamponade.

Abbreviation: PK, penetrating keratoplasty. fall, despite the fact that he was wearing eyeglasses. Although the graft-host junction was intact, choroidal hemorrhage occurred as a result of disruption of the upper scleral wound made at the time of extracapsular cataract extraction (Figure 2C). His right eye was repaired by multiple surgeries, including scleral suture, pars plana vitrectomy, encircling, and silicone oil tamponade (Figure 2D). In 2012, endothelial failure was noted in both eyes. The final BCVA in his right eye was 20/2000 and 20/500 in his left eye.

\section{Discussion}

Here we report on seven patients who experienced single and repeated globe rupture following penetrating keratoplasty in a total of eight eyes. In all except one eye, the rupture involved the graft-host junction; the time interval between penetrating keratoplasty and dehiscence of the graft-host junction ranged from 27 months to 15 years. In one eye (case 5-R), traumatic globe rupture involved the scleral wound from extracapsular cataract extraction performed 21 years before the rupture, while the graft-host junction of penetrating keratoplasty performed 23 years before the rupture remained intact. As previously reported, graft-host junction dehiscence can occur, regardless of the presence of sutures, as early as 3 days or as late as 30 years after penetrating keratoplasty. ${ }^{1-7}$ Case 5-R shows that both extracapsular cataract extraction scleral wound weakness and penetrating keratoplasty wound weakness can persist long after the operation has been performed.

During the 10-year study period, the incidence of globe rupture following penetrating keratoplasty at our hospital was approximately $2.8 \%$ (seven of 246 patients), similar to the previously reported incidence of $1.28 \%-5.8 \%{ }^{1-7}$ During the study period, our hospital performed 150 endothelial keratoplasties (eg, Descemet's stripping automated endothelial keratoplasty and Descemet's membrane endothelial keratoplasty), 25 deep anterior lamellar keratoplasties, and 13 anterior lamellar keratoplasties; however, no patients in these groups presented with globe rupture. These data support the idea that Descemet's stripping automated endothelial keratoplasty and Descemet's membrane endothelial keratoplasty maintain much of the globe's structural integrity. ${ }^{8}$ In deep anterior lamellar keratoplasty or anterior lamellar keratoplasty, an intact Descemet's membrane or posterior corneal portion might be considered to be a protective barrier. ${ }^{9-11}$ We did not perform femtosecond laser-assisted penetrating keratoplasty, which results in a zigzag-shaped wound that would, theoretically, provide an advantage if blunt trauma occurs. ${ }^{12}$ 
In our study, the final BCVA was $>20 / 200$ in three eyes $(37.5 \%)$, similar to previous reports. ${ }^{1-7}$ Fortunately, none of our patients needed evisceration, and none had a final BCVA of no light perception. Indeed, the rate of final BCVA of no light perception was $5.6 \%-25.5 \%$ in previous reports including large samples. ${ }^{1,2,4,5}$ Lens and posterior segment damage could be associated with a poor visual outcome, as previously reported, ${ }^{5-7}$ but a statistically significant difference was not found because of the small number of patients in our study.

In conclusion, the risk of post-penetrating keratoplasty globe rupture is significant and has a poor visual prognosis. The most common cause of globe rupture was falls in older patients. Patients should be informed before and after penetrating keratoplasty about the lifetime risk of globe rupture. Preventative measures (eg, wearing protective eye shields or goggles) should be taken to avoid single and repeated ocular trauma following penetrating keratoplasty.

\section{Acknowledgment}

This study was supported by a grant-in-aid for Scientific Research from the Japan Society for the Promotion of Science (Kakenhi, 22591934 and 23890072).

\section{Disclosure}

The authors report no conflicts of interest in this work.

\section{References}

1. Tran TH, Ellies P, Azan F, Assaraf E, Renard G. Traumatic globe rupture following penetrating keratoplasty. Graefes Arch Clin Exp Ophthalmol. 2005;243(6):525-530.

2. Das S, Whiting M, Taylor HR. Corneal wound dehiscence after penetrating keratoplasty. Cornea. 2007;26(5):526-529.

Clinical Ophthalmology

\section{Publish your work in this journal}

Clinical Ophthalmology is an international, peer-reviewed journal covering all subspecialties within ophthalmology. Key topics include: Optometry; Visual science; Pharmacology and drug therapy in eye diseases; Basic Sciences; Primary and Secondary eye care; Patient Safety and Quality of Care Improvements. This journal is indexed on
3. Hiratsuka Y, Sasaki S, Nakatani S, Murakami A. Traumatic wound dehiscence after penetrating keratoplasty. Jpn J Ophthalmol. 2007;51(2): 146-147.

4. Lam FC, Rahman MQ, Ramaesh K. Traumatic wound dehiscence after penetrating keratoplasty - a cause for concern. Eye (Lond). 2007;21(9): 1146-1150.

5. Kawashima M, Kawakita T, Shimmura S, Tsubota K, Shimazaki J. Characteristics of traumatic globe rupture after keratoplasty. Ophthalmology. 2009;116(11):2072-2076.

6. Steinberg J, Eddy MT, Katz T, Fricke OH, Richard G, Linke SJ. Traumatic wound dehiscence after penetrating keratoplasty: case series and literature review. Eur J Ophthalmol. 2012;22(3):335-341.

7. Tseng SH, Lin SC, Chen FK. Traumatic wound dehiscence after penetrating keratoplasty: clinical features and outcome in 21 cases. Cornea. 1999;18(5):553-558.

8. Bahar I, Kaiserman I, Levinger E, Sansanayudh W, Slomovic AR, Rootman DS. Retrospective contralateral study comparing Descemet stripping automated endothelial keratoplasty with penetrating keratoplasty. Cornea. 2009;28(5):485-488.

9. Zarei-Ghanavati S, Zarei-Ghanavati M, Sheibani S. Traumatic wound dehiscence after deep anterior lamellar keratoplasty: protective role of intact Descemet membrane after big-bubble technique. Cornea. 2010;29(2):220-221.

10. Lee WB, Mathys KC. Traumatic wound dehiscence after deep anterior lamellar keratoplasty. J Cataract Refract Surg. 2009;35(6): 1129-1131.

11. Chaurasia S, Ramappa M. Traumatic wound dehiscence after deep anterior lamellar keratoplasty. J AAPOS. 2011;15(5):484-485.

12. Kruger MM, Mootha VV. First report of traumatic globe rupture after femtosecond laser-assisted penetrating keratoplasty. Cornea. 2012;31(12):1504-1506.
PubMed Central and CAS, and is the official journal of The Society of Clinical Ophthalmology (SCO). The manuscript management system is completely online and includes a very quick and fair peer-review system, which is all easy to use. Visit http://www.dovepress.com/ testimonials.php to read real quotes from published authors. 